\title{
Infrared Spectra of Alternating Copolymer of Butadiene and Methyl Methacrylate
}

\author{
Junji Furukawa, Eiichi Kobayashi, ${ }^{*}$ and Yoshihiro Arai* \\ Department of Synthetic Chemistry, Faculty of Engineering, \\ Kyoto University, Kyoto 606, Japan.
}

(Received February 4, 1974)

\begin{abstract}
The infrared spectra of butadiene-methyl methacrylate alternating and random copolymers were investigated. It was found that the polarized infrared spectra of the elongated films of alternating copolymers showed a remarkable dichroism, whereas for the random copolymers, with poor stretching properties, dichroism could not be observed. The tentative assignments of the infrared spectra of the alternating copolymer were made with reference to the results for each homopolymer and the partially deuterated alternating copolymer prepared from 1,1,4,4-tetradeuterobutadiene and methyl methacrylate.

The X-ray diffraction diagram from an elongated film of the alternating copolymer showed a pattern of crystallization-imposed orientation. The characteristics of sequential regularity indicated by the X-ray data for the copolymer have been confirmed already with NMR data.

Similarities such as the identical $7.17 \AA$ period were recognized between the alternating copnlymers of butadiene-acrylonitrile and butadiene-methyl methacrylate.

KEY WORDS : Butadiene / Methyl Methacrylate / Alternating

Copolymer / Polarized IR Spectrum / IR Dichroism / X-Ray

Diagram / Assignment of IR Spectra / Identical Period of

Alternating Copolymer /
\end{abstract}

The infrared spectrum of the alternating copolymer of butadiene and acrylonitrile was almost identical to that of the random copolymer. ${ }^{1}$ However, appreciable differences were observed in the polarized infrared spectra measured with stretched samples of each copolymer. $^{2}$ The sequential regularity of the alternating copolymer favors orientation and crystallization under stretching so that it shows a pronounced infrared dichroism. This sequential regularity for the alternating copolymers of butadiene with acrylonitrile and butadiene with methyl methacrylate has already been confirmed by $100-$ and $220-\mathrm{MHz}$ NMR spectra. ${ }^{3}$

In the present work, the infrared spectrum and X-ray diffraction diagram of the alternating copolymer of butadiene and methyl methacrylate were studied. The tentative assignment of the infrared spectra of the copolymer was also investigated by using deuterobutadiene.

* Present address: Institute for Chemical Research, Kyoto University, Uji 611, Japan.

\section{EXPERIMENTAL}

$1,1,4,4$-Tetradeuterobutadiene (BD- $\left.d_{4}\right)$ was prepared according to the method of Ikeda, et $a l .{ }^{4} \quad$ The detailed procedures were described previously. ${ }^{2}$

The purification of the reagents and the polymerization procedures are almost the same as those in a previous report. ${ }^{5}$ The polymerization conditions and results are summarized in Table I.

The copolymer films were prepared by casting methylene chloride solutions of the copolymers on mercury metal followed by evaporating the solvent under reduced pressure. The films thus obtained were stretched to an elongation of about 8 times at $70-80^{\circ} \mathrm{C}$ and then clamped so as to retain their length. The films of random copolymer could be not elongated without rupture.

The infrared spectra of the copolymer films were measured with a Perkin-Elmer model 521 


\section{J. Furukawa, E. Kobayashi, and Y. Arai}

Table I. Polymerization conditions and results of BD-MMA copolymer in bulk

\begin{tabular}{|c|c|c|c|c|c|c|}
\hline Monomer & Catalyst & $\underset{{ }^{\circ} \mathrm{C}}{\text { Temp }}$ & $\underset{\mathrm{hr}}{\operatorname{Time}}$ & $\underset{\%}{\text { Conv, }}$ & $\begin{array}{l}\text { [MMA] in } \\
\text { copolymerc }^{\circ} \%\end{array}$ & $\begin{array}{l}{[\eta]^{\mathrm{d}},} \\
\mathrm{d} l / \mathrm{g}\end{array}$ \\
\hline BD-MMA & $\mathrm{EtAlCl}_{2}-\mathrm{VOCl}_{3}{ }^{\mathrm{a}}$ & 0 & 20 & 12.5 & 52.0 & 4.1 \\
\hline BD- $d_{4}-\mathrm{MMA}$ & $\mathrm{EtAlCl}_{2}-\mathrm{VOCl}_{3}$ & 0 & 4 & 63 & 51.7 & 1.8 \\
\hline BD-MMA & Benzoyl peroxide ${ }^{b}$ & 50 & 3 & 3.1 & 62.9 & 一 \\
\hline $\mathrm{BD}-d_{4}-\mathrm{MMA}$ & Benzoyl peroxide & 50 & 7.5 & 4.9 & 55.4 & 0.5 \\
\hline
\end{tabular}

a $\left[\mathrm{EtAlCl}_{2}\right] /\left[\right.$ Total monomer], $1 / 25 ;\left[\mathrm{VOCl}_{3}\right] /\left[\mathrm{EtAlCl}_{2}\right], 1 / 100$.

b [Benzoyl peroxide]/[Total monomer], 1/50.

c The copolymer composition was calculated from the elemental analysis of oxygen.

d $[\eta]$ was determined in toluene at $30^{\circ} \mathrm{C}$.
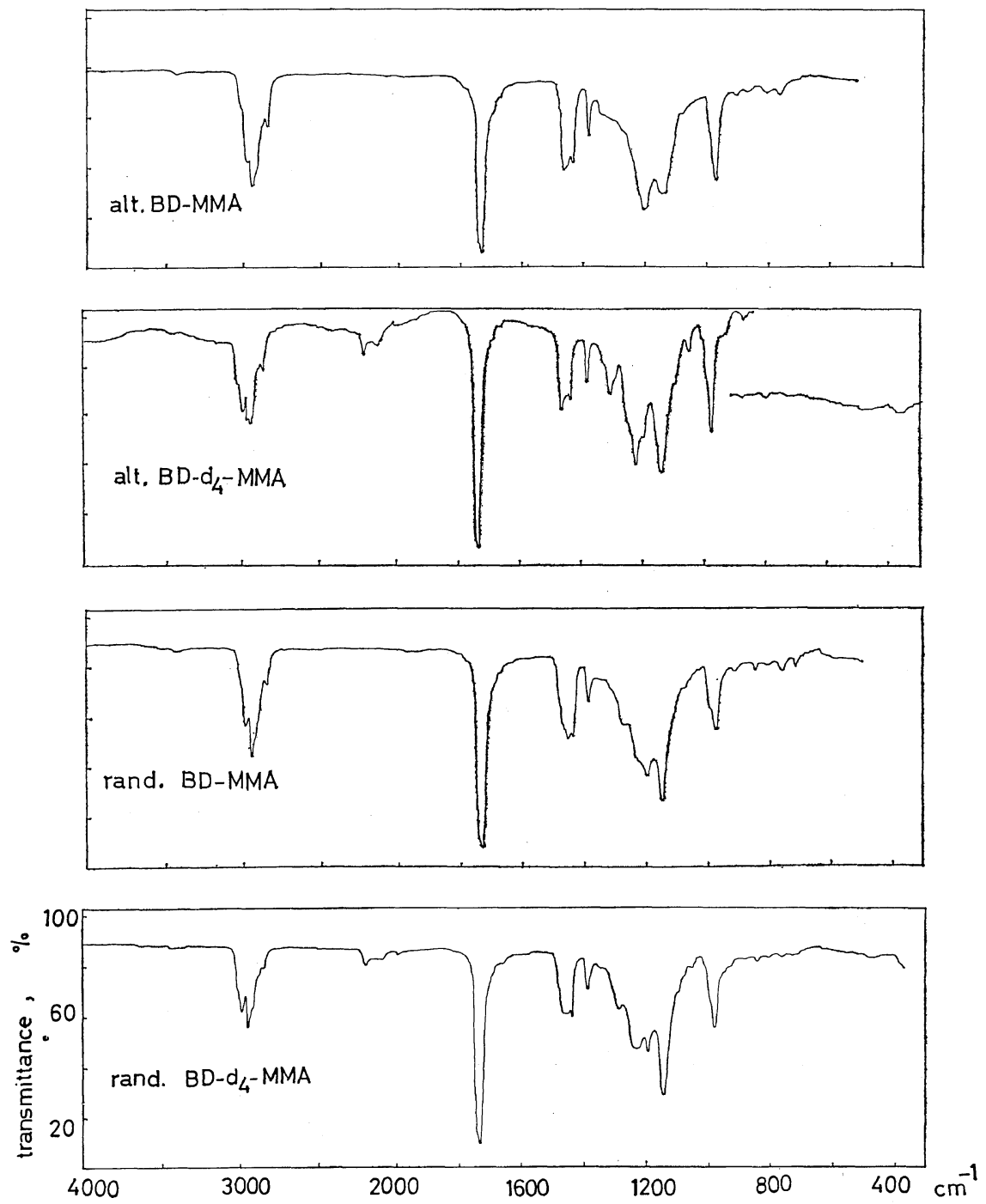

Figure 1. Infrared spectra of alternating BD-MMA, BD- $d_{4}-\mathrm{MMA}$ copolymer, and random BD-MMA, BD- $d_{4}-\mathrm{MMA}$ copolymer. 
grating spectrophotometer. Polarized spectra were recorded on the same instrument equipped with a wire grid polarizer. Differential polarized spectra $^{6}$ of the copolymer films were obtained with a Hitachi model EPI-S2 infrared spectrophotometer equipped with two silver chloride polarizers. These were measured at room temperature. The X-ray diffraction diagram was obtained with Shimadzu GX-2 X-ray diffractometer at room temperature.

\section{RESULTS}

The infrared spectra of the unstretched film of the alternating copolymer of butadiene and methyl methacrylate and the random copolymer together with their deuterated analogues are shown in Figure 1. Some of the spectral absorptions are similar to those of the alternating copolymers of butadiene and acrylonitrile. Namely, the diene unit in the alternating copolymers is in the trans-1, 4-configuration $\left(970 \mathrm{~cm}^{-1}\right)$, with the vinyl $\left(993 \mathrm{~cm}^{-1}\right)$ and/or cis-1, 4-configuration $\left(740 \mathrm{~cm}^{-1}\right)$ almost or completely unobserved. The spectra of the alternating copolymers of butadiene and methyl methacrylate are almost identical to those of the random one. However, the bands in the region from 1300 to $1200 \mathrm{~cm}^{-1}$, which corresponds to the tacticity-sensitive area for poly(methyl methacrylate), ${ }^{7}$ are somewhat different from each other.

The polarized infrared spectra of the alternating copolymer films stretched by $700 \%$ are shown in Figure 2. The solid and broken lines represent the absorption curves obtained for the polarized radiation with the electric vectors perpendicular $(\sigma)$ and parallel $(\pi)$ to the stretching direction, respectively. The infrared dichroism is evident in the alternating copolymer of butadiene and methyl methacrylate just as it is in the copolymer of butadiene and acrylonitrile. ${ }^{2}$ However, the infrared dichroism of the random copolymer of butadiene and methyl methacrylate could not be measured. The differential polarized infrared spectra of the alternating copolymer films stretched by $700 \%$ are shown in Figure 3. The bands perpendicular $(\sigma)$ and parallel $(\pi)$ to the stretching direction are shown by downward and upward peaks, respectively. Strong perpendicular peaks appear at 2910, 1740, $1710,1465,1380,1330,1220$, and $965 \mathrm{~cm}^{-1}$ and parallel peaks at 2970,1665 and $920 \mathrm{~cm}^{-1}$ : The polarized and the differential polarized infrared
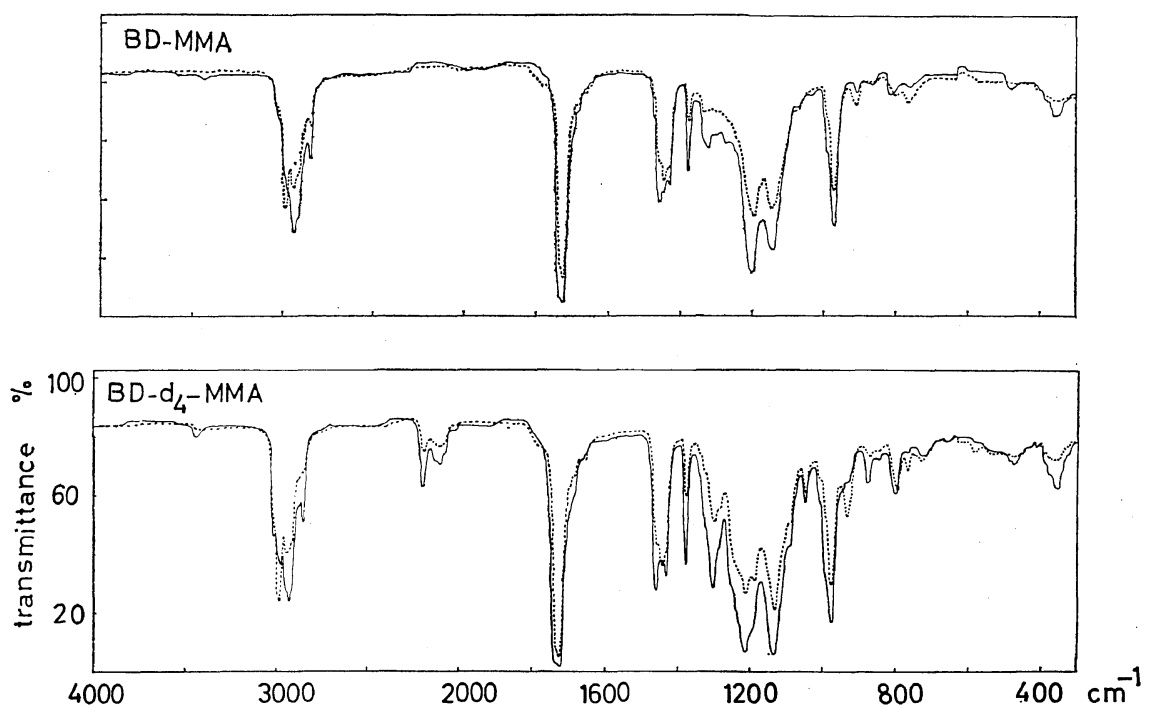

Figure 2. Polarized spectra of alternating BD-MMA and BD- $d_{4}-\mathrm{MMA}$ copolymer film elongated by 700\%: (-), electric vector perpendicular to direction of stretch; (-----), electric vector parallel to direction of stretch. 

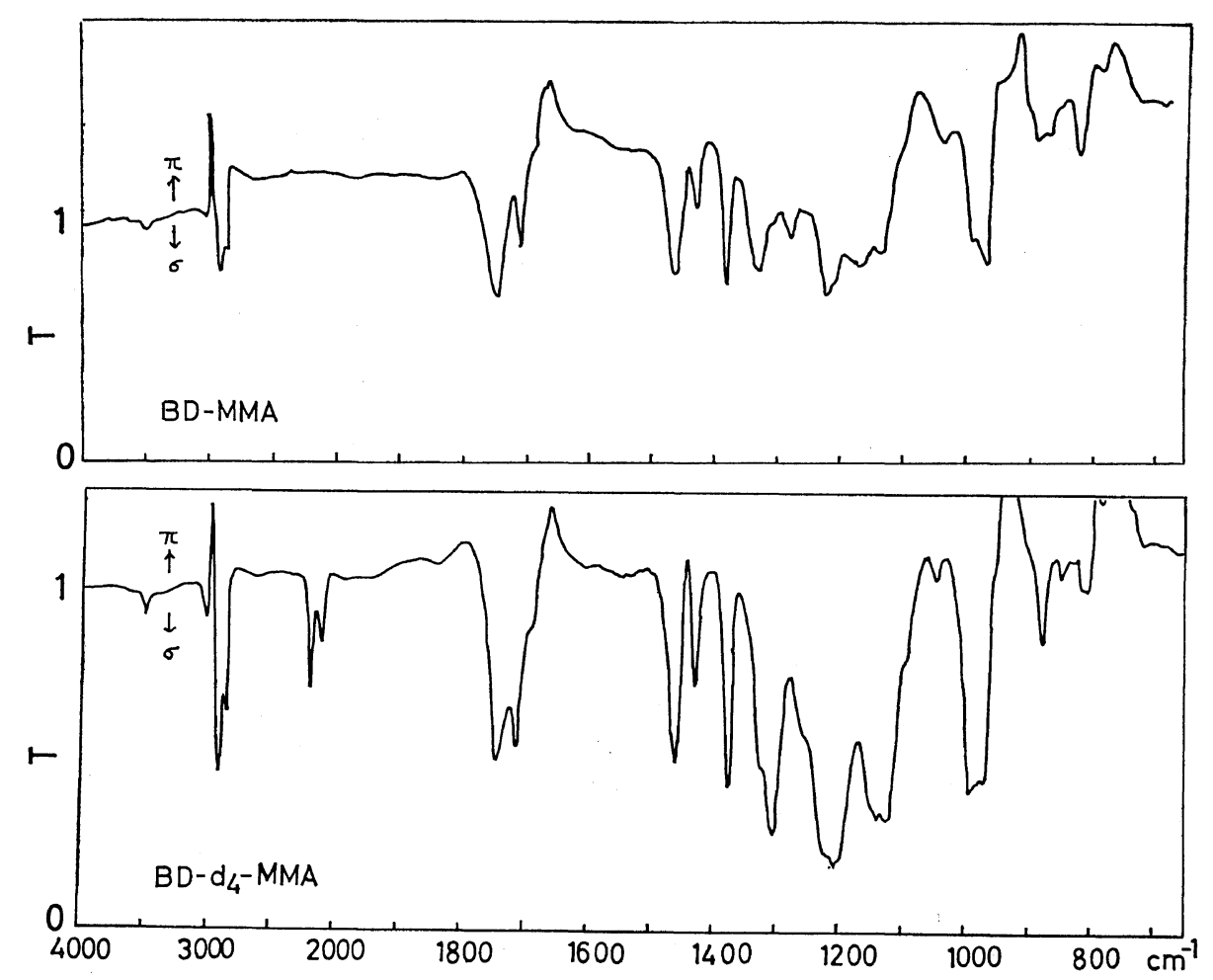

Figure 3. Differential polarized spectra of alternating BD-MMA and BD- $d_{4}-$ MMA copolymer film elongated by $700 \%$.

spectra of the alternating copolymer suggest that the sequentially regular copolymer favors generating molecular orientation under stretching.

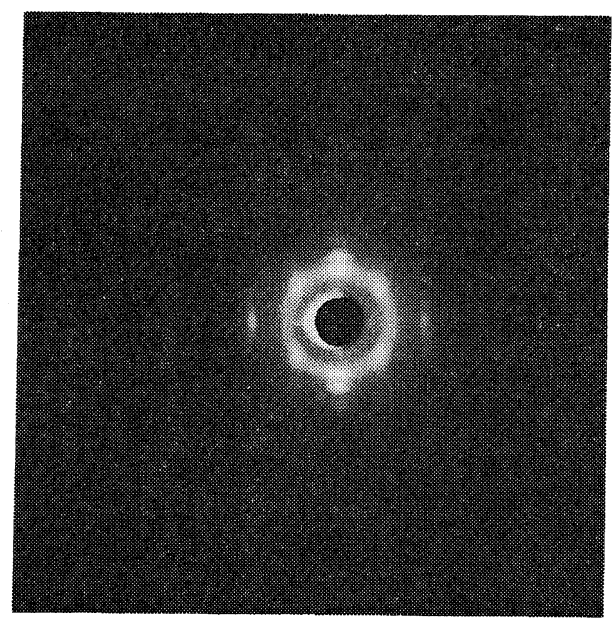

Figure 4. X-Ray diffraction diagram of alternating copolymer of BD-MMA elongated by $700 \%$.
In fact, the X-ray diffraction diagram of the stretched copolymer film indicates a pattern of crystallization-imposed orientation as shown in Figure 4. A repetetive interval of $7.17 \AA$ is calculated from the X-ray diffraction pattern. This seems to differ from the repetetive interval of a planar-zigzag chain structure of $7.5 \AA^{2}$ estimated from a molecular model, and suggests a somewhat twisted chain conformation as mentioned in a previous paper. ${ }^{2,3}$

\section{DISCUSSION}

The frequency, relative intensity, polarization, and tentative assignment of the alternating copolymer and deuterated analogues are listed in Table II. The assignment was attempted by referring to that of poly(methyl methacrylate) ${ }^{7}$ and that of trans-1, 4-polybutadiene. ${ }^{8,9}$

The band at $3430 \mathrm{~cm}^{-1}$ is easily assigned to the overtone of the $\mathrm{C}=\mathrm{O}$ stretching vibration at $1728 \mathrm{~cm}^{-1}$. The alternating copolymer of 
Infrared Spectra of BD-MMA Alternating Copolymer

Table II. Infrared spectra of alternating BD-MMA and BD- $d_{4}-$ MMA copolymer (from Figure 1)

\begin{tabular}{|c|c|c|c|c|c|c|}
\hline \multicolumn{3}{|c|}{ BD-MMA } & \multicolumn{3}{|c|}{ BD- $d_{4}-\mathrm{MMA}$} & \multirow{2}{*}{$\begin{array}{l}\text { Tentative } \\
\text { assignment }\end{array}$} \\
\hline Frequency, & $\begin{array}{l}\text { Relative } \\
\text { intensity }\end{array}$ & $\begin{array}{l}\text { Polari- } \\
\text { zation }\end{array}$ & $\underset{\mathrm{cm}^{-1}}{\text { Frequency }}$ & intensity ${ }^{\mathrm{a}}$ & $\begin{array}{l}\text { Polari- } \\
\text { zation }\end{array}$ & \\
\hline 3430 & vw, b & $\sigma$ & 3430 & $v w, b$ & $\sigma$ & $2 \nu(\mathrm{C}=\mathrm{O})[\mathrm{MMA}]$ \\
\hline 3020 & $\mathrm{~m}, \mathrm{sh}$ & $\sigma$ & 3010 & $\mathrm{sh}$ & $\sigma$ & $\nu(\mathrm{CH})[\mathrm{BD}]$ \\
\hline 2970 & $\mathrm{~m}, \mathrm{sh}$ & $\pi$ & 2978 & $\mathrm{~m}$ & $\pi$ & $\nu_{\mathrm{a}}\left(\mathrm{CH}_{3}-\mathrm{O}\right)[\mathrm{MMA}]+\nu_{\mathrm{a}}\left(\mathrm{CH}_{2}\right)[\mathrm{MMA}]$ \\
\hline 2940 & $\mathbf{s}$ & $\sigma$ & $\begin{array}{l}2940 \\
2928\end{array}$ & $\begin{array}{l}\mathrm{m}, \mathrm{sh} \\
\mathrm{s}\end{array}$ & $\begin{array}{l}\sigma \\
\sigma\end{array}$ & 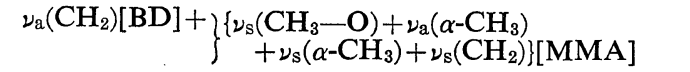 \\
\hline 2920 & $\operatorname{sh}$ & $\sigma$ & 2915 & sh & $\sigma$ & $\begin{array}{l}\text { Combination band associated with ester } \mathrm{CH}_{3} \text { group } \\
\text { [MMA] }\end{array}$ \\
\hline 2875 & $\operatorname{sh}$ & $\sigma$ & 2873 & sh & $\sigma$ & Combination band [MMA] \\
\hline 2845 & $\mathrm{~m}$ & $\sigma$ & $\begin{array}{l}2848 \\
2193 \\
2100\end{array}$ & $\begin{array}{l}\mathrm{m} \\
\mathrm{m} \\
\mathrm{m}, \mathrm{b}\end{array}$ & $\begin{array}{l}\sigma \\
\sigma \\
\sigma\end{array}$ & $\begin{array}{l}\left.\nu_{\mathrm{s}}\left(\mathrm{CH}_{2}\right)[\mathrm{BD}]+\right\} \text { Combination band }[\mathrm{MMA}] \\
\nu_{\mathrm{a}}\left(\mathrm{CD}_{2}\right)[\mathrm{BD}] \\
\nu_{\mathrm{s}}\left(\mathrm{CD}_{2}\right)[\mathrm{BD}]\end{array}$ \\
\hline 1736 & vs, sh & $\sigma$ & 1738 & vs & $\sigma$ & \}$_{\nu}(\mathrm{C}=\mathrm{O})[\mathrm{MMA}]$ \\
\hline 1728 & vs & $\sigma$ & 1730 & vs & $\sigma$ & \}$\left.^{\nu(C}=0\right)[$ ININA] \\
\hline 1665 & w & $\pi$ & 1660 & $\mathrm{w}$ & $\pi$ & $\nu(\mathrm{C}=\mathrm{C})[\mathrm{BD}]$ \\
\hline 1473 & $\operatorname{sh}$ & $\sigma$ & 1473 & $\mathrm{sh}$ & $\sigma$ & $\delta_{\mathrm{a}}\left(\alpha-\mathrm{CH}_{3}\right)[\mathrm{MMA}]$ \\
\hline 1460 & s & $\sigma$ & 1458 & s & $\sigma$ & $\delta_{\mathrm{a}}\left(\mathrm{CH}_{3}-\mathrm{O}\right)[\mathrm{MMA}]$ \\
\hline 1448 & s, sh & $\sigma$ & & & & $\delta\left(\mathrm{CH}_{2}\right)[\mathrm{BD}]$ \\
\hline 1430 & $\mathrm{~s}$ & $\sigma$ & 1430 & s & $\sigma$ & $\left\{\delta\left(\mathrm{CH}_{2}\right)+\delta_{\mathrm{s}}\left(\mathrm{CH}_{3}-\mathrm{O}\right)\right\}[\mathrm{MMA}]$ \\
\hline 1380 & s & $\sigma$ & 1377 & s & $\sigma$ & $\delta_{\mathrm{s}}\left(\mathrm{O}-\mathrm{CH}_{3}\right)[\mathrm{MMA}]$ \\
\hline 1345 & $\mathrm{sh}, \mathrm{b}$ & $\sigma$ & & & & $\omega\left(\mathrm{CH}_{2}\right)[\mathrm{BD}]+$ \\
\hline & & & $\begin{array}{l}1320 \\
1300\end{array}$ & $\begin{array}{l}\mathrm{sh} \\
\mathrm{s}\end{array}$ & $\sigma$ & $\omega(\mathrm{CH})[\mathrm{BD}]+\omega\left(\mathrm{CH}_{2}\right)[\mathrm{MMA}]+\left\{\nu_{\mathrm{a}}(\mathrm{C}-\mathrm{C}-\mathrm{O})\right.$ \\
\hline 1295 & $\mathrm{sh}, \mathrm{b}$ & $\sigma$ & 1290 & sh & $\sigma$ & {$[+\nu(\mathrm{C}-\mathrm{O})\}[\mathrm{MMA}]$} \\
\hline 1268 & $\mathrm{sh}, \mathrm{b}$ & $\sigma$ & & & & \\
\hline 1245 & $\mathrm{sh}, \mathrm{b}$ & $\sigma$ & 1245 & $\mathrm{sh}$ & $\sigma$ & 1. \\
\hline 1216 & $\mathrm{sh}$ & $\sigma$ & 1216 & vs & $\sigma$ & \\
\hline 1198 & vs, b & $\sigma$ & 1193 & $\mathrm{~m}, \mathrm{sh}$ & $\sigma$ & $\mathrm{t}\left(\mathrm{CH}_{2}\right)[\mathrm{BO}]+\left\{\begin{array}{l}\nu(\mathrm{C}-\mathrm{C})[\mathrm{MMA}]+\text { Skeletal stretching } \\
\text { coupled with internal CH } \\
\text { deformation vibration [MMA] }\end{array}\right.$ \\
\hline 1140 & vs & $\sigma$ & $\begin{array}{l}1136 \\
1090\end{array}$ & $\begin{array}{l}\text { vs } \\
\text { sh }\end{array}$ & $\sigma$ & ${ }_{-}$ \\
\hline 1080 & vw & $\pi$ & $\begin{array}{l}1065 \\
1050 \\
1010\end{array}$ & $\mathrm{vw}, \mathrm{sh}$ & $\begin{array}{l}- \\
\sigma \\
\sigma\end{array}$ & $\begin{array}{l}\nu(\mathrm{C}-\mathrm{C})[\mathrm{BD}] \\
\delta\left(\mathrm{CD}_{2}\right)[\mathrm{BD}] \\
\omega\left(\mathrm{CD}_{2}\right)[\mathrm{BD}]\end{array}$ \\
\hline 993 & $\mathrm{sh}$ & $\sigma$ & 992 & sh & $\sigma$ & $\left\{\left\{\nu_{\mathrm{s}}(\mathrm{C}-\mathrm{O}-\mathrm{C})+\gamma\left(\mathrm{CH}_{3}-\mathrm{O}\right)\right\}[\mathrm{MMA}]\right.$ \\
\hline 970 & vs & $\sigma$ & 975 & vs & $\sigma$ & 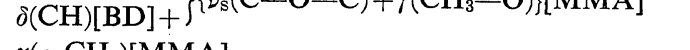 \\
\hline 905 & $\mathrm{w}$ & $\pi$ & $\begin{array}{l}935 \\
875\end{array}$ & $\begin{array}{l}\mathrm{sh}, \mathrm{b} \\
\mathrm{w}\end{array}$ & $\pi$ & $\begin{array}{l}\gamma\left(\alpha-\mathrm{CH}_{3}\right)[\mathrm{MMA}] \\
\mathrm{t}\left(\mathrm{CD}_{2}\right)[\mathrm{BD}]\end{array}$ \\
\hline 805 & $\mathrm{w}, \mathrm{b}$ & - & 800 & $w, b$ & 一 & $\longrightarrow^{d}$ \\
\hline 762 & vw, b & $\pi$ & $\begin{array}{l}765 \\
730\end{array}$ & $\begin{array}{l}\mathrm{vw} \\
\mathrm{vw}, \mathrm{b}\end{array}$ & $\pi$ & \}$\left\{\nu(\mathrm{C}-\mathrm{C})+\gamma\left(\mathrm{CH}_{2}\right)\right\}[\mathrm{BD} \text { and } \mathrm{MMA}]^{\mathrm{d}}$ \\
\hline & & & $580^{c}$ & vw & $\pi$ & $\gamma\left(\mathrm{CD}_{2}\right)[\mathrm{BD}]+$ \\
\hline $\begin{array}{l}480^{c} \\
355^{c}\end{array}$ & $w, b$ & $\sigma$ & $475^{c}$ & $w, b$ & $\sigma$ & $\delta(\mathrm{C}-\mathrm{C}-\mathrm{O})[\mathrm{MMA}]^{\mathrm{d}}$ \\
\hline $355^{c}$ & $w, b$ & $\sigma$ & $360^{c}$ & $\mathrm{~m}, \mathrm{~b}$ & $\sigma$ & $\longrightarrow^{\mathrm{d}}$ \\
\hline
\end{tabular}

a s, strong; m, medium; w, weak; v, very; sh, shoulder; b, broad.

b [MMA], of methyl methacrylate unit; [BD], butadiene unit; $\nu$, stretching; $\nu_{a}$, asymmetric stretching; $\nu_{\mathrm{S}}$, symmetric stretching; $\delta$ bending; $\omega$, wagging; $t$, twisting; $\gamma$, rocking.

c See Figure 2.

d They may correspond to crystalline sensitive band. 


\section{J. Furukawa, E. Kobayashi, and Y. Arai}

butadiene and methyl methacrylate possesses various kinds of $\mathrm{CH}_{3}, \mathrm{CH}_{2}$ and $\mathrm{CH}$, and consequently, the assignment of these modes is rather difficult, because the band contains contributions from combinations or overlaps of the fundamentals. The perpendicular band at $3020 \mathrm{~cm}^{-1}$ is assigned to the $\mathrm{CH}$ stretching mode and is retained in the BD- $d_{4}-$ MMA copolymer. The bands at 2970,2940,2920, 2875, and 2845 $\mathrm{cm}^{-1}$ are all associated with the ester methyl group. The former two are assigned mainly to the fundamental vibrations of the asymmetric and symmetric stretching of the ester methyl group, and the latter three the combination bands associated with the ester methyl group as shown in Table II. The modes corresponding to poly(methyl methacrylate) were observed at 2995, 2948, 2920, and $2835 \mathrm{~cm}^{-1}$. $^{7}$ These facts are consistent with the above assignment. The band at $2940 \mathrm{~cm}^{-1}$ probably contains the $\mathrm{CH}_{2}$ asymmetric stretching mode of the butadiene unit. This is reasonable from the fact that the frequencies are intermediate between those of trans-1, 4-polybutadiene and poly(methyl methacrylate). Furthermore, this band is reduced in intensity but does not disapper completely on deuterating the $\mathrm{CH}_{2}$ group of the butadiene unit. The band at $2845 \mathrm{~cm}^{-1}$ is assigned to the overlapping absorption of the $\mathrm{CH}_{2}$ symmetric stretching mode of the butadiene unit and the combination associated with the ester methyl group. These assumptions are rationalized by a comparison of the intensities of the nondeuterated polymer with those of the deuterated one prepared from BD- $d_{4}$. The reasonable values of 1.34 and 1.35 are found respectively for the $\mathrm{CH}_{2} / \mathrm{CD}_{2}$ frequency ratios of the asymmetric and symmetric vibrational frequencies.

The $\mathrm{C}=\mathrm{O}$ stretching $(\sigma)$ and the $\mathrm{C}=\mathrm{C}$ stretching $(\pi)$ mode are responsible for the doublet at 1736 and $1728 \mathrm{~cm}^{-1}$ and the band at $1665 \mathrm{~cm}^{-1}$, respectively. The absorption intensity of the $\mathrm{C}=\mathrm{C}$ stretching mode of the butadienemethyl methacrylate alternating copolymer is weaker than that of the butadiene-acrylonitrile alternating copolymer. ${ }^{2}$ This may be concerned with the symmetry of the molecular structure with respect to the stereospecificity of the $\alpha$ carbon in the acrylic monomer unit.
In the spectrum of the alternating copolymer, the $\mathrm{CH}$ bending modes of the $\alpha-\mathrm{CH}_{3}, \mathrm{O}-\mathrm{CH}_{3}$ and the two kinds of $\mathrm{CH}_{2}$ are observed in the region from 1473 to $1380 \mathrm{~cm}^{-1}$. The $\mathrm{CH}_{2}$ bending mode of the butadiene unit is responsible for the band at $1448 \mathrm{~cm}^{-1}$ which disappears on deuteration of the butadiene unit. This mode for the alternating copolymer of butadiene and acrylonitrile appeared at $1440 \mathrm{~cm}^{-1} .^{2}$ The band at $1345 \mathrm{~cm}^{-1}$, which disappears on deuteration of the butadiene $\mathrm{CH}_{2}$ group, is assigned to the $\mathrm{CH}_{2}$ wagging vibrations of the butadiene unit. The corresponding $\mathrm{CD}_{2}$ vibration in the BD- $d_{4}-$ MMA copolymer is observed at 1010 $\mathrm{cm}^{-1}$. The ratio of the $\mathrm{CH}_{2}$ vibrational frequency to the $\mathrm{CD}_{2}$ one is 1.33 .

The bands at wavenumbers lower than about $1300 \mathrm{~cm}^{-1}$ are rather complicated, because the region contains contributions from combinations and overlappings of the fundamental together with the skeletal modes. The broad band at $1295 \mathrm{~cm}^{-1}$ may originate from the two wagging modes of the methyl methacrylate $\mathrm{CH}_{2}$ group and the butadiene $\mathrm{CH}$ group. The two inflections at 1268 and $1245 \mathrm{~cm}^{-1}$ seem to correspond to the 1270 and $1240 \mathrm{~cm}^{-1}$ doublet of syndiotactic poly(methyl methacrylate), which Nagai has assigned to $\nu_{\mathrm{a}}(\mathrm{C}-\mathrm{C}-\mathrm{O})$ coupled with $\nu(\mathrm{C}-\mathrm{O}){ }^{7}$ However, the corresponding inflection at 1245 $\mathrm{cm}^{-1}$ in the deuterobutadiene-methyl methacrylate copolymer resembles the single absorption of isotactic poly(methyl methacrylate) at 1249 $\mathrm{cm}^{-1}$. But these absorption intensities are very weak and they do not offer exact information corresponding to cotacticity of the alternating copolymer. According to the $220-\mathrm{MHz}$ NMR spectrum of deuterobutadiene-methyl methacrylate alternating copolymer an isotactic configuration flanked by butadiene units was suggested. Either way, these inflections may be due to the vibrational modes of methyl methacrylate unit described as $\nu_{a}(\mathrm{C}-\mathrm{C}-\mathrm{O})$ in Table II. The assigment of these bands may be a skeletal stretching mode coupled with the internal $\mathrm{CH}$ deformation modes, as has been pointed out by Nagai. ${ }^{7}$ In particular, the contribution from the $\mathrm{C}-\mathrm{C}-\mathrm{O}$ asymmetric stretching mode is large as is deduced from the high intensity of these bands. 
The parallel band at $1080 \mathrm{~cm}^{-1}$ is probably assigned to the $\mathrm{C}-\mathrm{C}$ stretching mode. The band at $1050 \mathrm{~cm}^{-1}$ is reasonably assigned to the $\mathrm{CD}_{2}$ bending mode. The $\mathrm{C}-\mathrm{O}-\mathrm{C}$ symmetric stretching and the $\mathrm{O}-\mathrm{CH}_{3}$ rocking mode are responsible for the bands at 993 and $970 \mathrm{~cm}^{-1}$. The parallel band at $905 \mathrm{~cm}^{-1}$ shifted to 935 $\mathrm{cm}^{-1}$ on deuteration of the butadiene unit. This band is easily assigned to the $\alpha-\mathrm{CH}_{3}$ rocking mode.

The intensity of the bands at 805 and $762 \mathrm{~cm}^{-1}$ increased with stretching of the copolymer film. In the spectra of poly(methyl methacrylate), it is pointed out that the bands near $750 \mathrm{~cm}^{-1}$ increase in intensity owing to crystallization. ${ }^{7}$ This band may be associated with a crystallization-sensitive band. The parallel band at 762 $\mathrm{cm}^{-1}$ for the nondeuterated copolymer and the bands $765,730 \mathrm{~cm}^{-1}$ for the deuterated one may be associated with the $\mathrm{C}-\mathrm{C}$ stretching and the $\mathrm{CH}_{2}$ rocking mode. The assignment of the absorptions at 1090,805 and $355 \mathrm{~cm}^{-1}$ are uncertain at present.

In conclusion, the molecular structures of butadiene-acrylonitrile or - methyl methacrylate alternating copolymer in the crystalline resion, have nearly identical repetetive intervals of 7.14-7.17 $\AA$. This may reflect the high sequence regularity and similar crystalline structure of these alternating copolymers prepared by similar polymerization mechanisms. ${ }^{5}$

Acknowledgment. The authors wish to express his grateful to Dr. J. Umemura (Institute for Chemical Research, Kyoto University) for his kind guidance through the assignment of the infrared spectra.

\section{REFERENCES}

1. J. Furukawa, Y. Iseda, K. Haga, and N. Kataoka, J. Polym. Sci., Part A-1, 8, 1147 (1970).

2. J. Furukawa, E. Kobayashi, K. Uratani, Y. Iseda, J. Umemura, and T. Takenaka, Polymer J., 4, 358 (1973).

3. T. Suzuki, Y. Takegami, J. Furukawa, E. Kobayashi, and Y. Arai, ibid., 4, 657 (1973).

4. S. Ikeda, Y. Tanaka, and T. Morishima, Annual Meeting, Soc. High Polymer Sci., Nagoya, 1962, p 79.

5. J. Furukawa, E. Kobayashi, Y. Iseda, and Y. Arai, Polymer J., 1, 442 (1970).

6. R. Gotoh, T. Takenaka, and N. Hayama, Kolloid-Z. Z. Polym., 205, 18 (1965).

7. H. Nagai, J. Appl. Polym. Sci., 7, 1697 (1963).

8. V. N. Nikitin and N. V. Mikhailova, Vysokomol. Soedin., Ser. A, 9, 784 (1967).

9. N. Neto and C. Di Lauro, Eur. Polym. J., 3, 645 (1967). 